From The SAGE Encyclopedia of Theory in Psychology, (2016), H.L. Miller (ed.). Thousand Oaks, CA: Sage Publications, vol. 1., pp. 409-411.

\title{
Heightened Consciousness
}

Heightened consciousness has become a common expression in daily conversations, but it expresses a number of different concepts depending on the meaning of the speaker and is related to other phrases or terms that have slightly different connotations. This entry explores the different meanings of the term heightened consciousness and similar phrases in regard to personal development.

The phrase may merely refer to a state of increased alertness, as when one feels endangered or on the verge of an exciting breakthrough. One may also use the phrase to indicate a sense of new understanding or awakening to a new a perspective; expanded consciousness is used in this same way, without the vertical implications. One may make reference to getting high or being on a high, both implying simply feeling good, though the former also hints that externally supplied chemicals are involved. Politically, certain groups like feminists or critical theorists (for example, Paulo Freire) have written of consciousness-raising, meaning to awaken to the oppression that one has been conditioned to accept.

Another meaning of heightened consciousness refers to breaking through the habitual patterns or limitations of one's ego or self-concept to new awareness. Beyond these meanings is the use of the phrase to express transcending the isolation of one's inner self in a mystical experience in which self and world or self and God are united.

\section{Stages of Development}

It is generally assumed that infants can make little differentiation between self and world, and it is this differentiation that marks a first, early stage. The discovery of one's body, motion, and control of the environment soon follows. However, it is only when the toddler begins to interact (play) cooperatively with others that a sense of self and other emerges. This is soon followed by the beginnings of language acquisition late in the second year enabling the child to refer to herself as me or I (the so-called "mirror stage") and to gain self-consciousness around five years old when narrative memories usually begin.

Cooperative play and shared intentionality are necessary for language development and cultural integration, so the child who enters this stage is able to learn with others and to gain a similar understanding of the culture-world in which $\mathrm{s} / \mathrm{he}$ is immersed. As children mature, they gain independence, the ability to control their impulses and to think in the abstract more freely. At this point, they are usually thought to enter adulthood and guide themselves (and significant others) through a lifetime. 
Except in the more mundane definitions mentioned above (for example, being on a high or expanding consciousness with knowledge), most widely cited developmental psychologists do not postulate a heightened-consciousness stage that transcends or at least decenters the mature ego. The best-known stage theory is Jean Piaget's, but his final stage - "formal operations", meaning abstract thought begins when the child is 11 or 12 years old and no further cognitive stages are ahead. Albert Bandura views the individual as having achieved full personhood with adult self-efficacy - that is, confident decision-making. Erik Erikson's stages of psychosocial identity may suggest a sort of heightened consciousness when one enters old age and fully embraces one's past, but this is more like the generalized wisdom sometimes attributed to the elderly.

There are notable exceptions, however, as well as whole areas of thought beyond developmental psychology in which such higher states of awareness are the purpose of life. Lawrence Kohlberg, who modeled his early moral stages of development on Piaget's, went further than Piaget in positing a postconventional sixth stage wherein individuals use abstract thought to take the perspective of another and possibly stand against the conventions of their own culture. Kohlberg then moved into controversial territory by speculating a last, seventh stage only a rare few ever attain that he called transcendental morality, that is, the discovery of universal morality, which sounds much like the highest stage of attainment of the philosopher-king in Plato's Republic.

Similarly, Abraham Maslow's well-known hierarchy of human needs originally had self-actualization at its pyramidal summit; this is the state of mature confidence in which one can express oneself creatively without anxiety over being judged by others. After discovering the human-potential movement, Maslow added another level, even rarer (presumably floating above his pyramid) that he called selftranscendence. Influenced by postmodernism, Robert Kegan also added a stage of consciousness beyond his previous final stage of mature, loving adulthood in which even the sense of oneself as a distinct individual is transformed into interindividuality. To this list must be added Mihaly Csikszentmihalyi's concept of flow, which also refers to a stage of heightened, or even self-transcendent, consciousness.

\section{Heightened Consciousness As Self-transcendence}

It appears, then, to many psychologists, developmental or otherwise, that there naturally exists an attainable state that might be known as heightened consciousness. Most of us, however, will be lucky to achieve and retain the confident ego of mature adulthood, as we often slip back to earlier stages of cognitive or emotional development (and some never manage to leave them). A few of the theorists consider the state of heightened consciousness so rare that they list examples from the usual great suspects like Gandhi, Mother Teresa, Martin Luther King, Buddha, etc., but the majority opinion seems to be that heightened consciousness is a state that implies degrees of self-transcendence (going beyond 
the inner monologues of self-centeredness) that are, at least occasionally, attained by most people.

The psychoanalyst C. G. Jung wrote of individuation as the crisis that, for many, begins after middle age in the discovery that their economic stability or social achievements leave them craving for deeper meaning. This is why he called his work depth psychology. (Jung obviously did not work with the poor or disenfranchised.) If the individual successfully negotiated the trials and tribulations of doubt, fear, anxiety, and disturbing dreams and fantasies, she would have decentered her ego-self (the objective self, learned from the outside-in) and found a new center of consciousness in the Self (the capitalized version suggests soul, though Jung avoided that term because of its religious connotations).

The Self is the doorway to what Jung called the collective unconscious, the bottomless repository of all life experience on Earth, which he sometimes characterized as being the anima mundi, the soul of the world. One who had individuated appeared no different on the outside, except that he or she was more alive, more focused outwardly on the world and other people for reasons that had nothing to do with personal gain. The individual's heightened consciousness indicated that he or she had discovered (or created) a meaning to her life that was beyond the superficial needs of the ego for acceptance or recognition.

This state will sound familiar to anyone who has read so-called Eastern philosophy. Transcending the ego, both in Buddhism and certain sects of Hinduism, means awakening to higher consciousness. Often, after years of meditation or asceticism, a transcendent experience occurs - sometimes called moksha in India and satori in Japanese Zen Buddhism. In Indian Buddhism, Jainism, and some Hinduism, the ego dissipates and becomes the Ätman (much like Jung's Self), which, in Hinduism, identifies with Brahman (absolute reality; here, now, and beyond; a deity). Buddhism calls this entering Nirvana (absolute nothingness, egolessness, not a deity).

These "Eastern" disciplines that seek awakening or the highest consciousness by extinguishing the ego appear much different than those of the West that more often portray the ego only as decentered, that is, put aside until needed as a social mask (persona).

D. T. Suzuki, a Japanese monk who taught the West about Zen Buddhism, has suggested that transcending the self does not mean attaining hidden spiritual treasure or finding union with God. In fact, he makes the point that we moderns have lost our sense of meaning by losing touch with the very real world around us in the self-made prison of ego (or self-consciousness). For Suzuki, "To transcend' suggests 'going beyond,' 'being away from,' that is, a separation, a dualism. I have, however, no desire to hint that the 'something' stands away from the world in which we find ourselves" (1964, p. 196) 


\section{Transformative Experience}

It seems clear that heightened consciousness is an actual state of awareness beyond mundane, daily consciousness, but its interpretation into words limits understanding and draws it into cultural relativity. A reader who has never had such an experience may well wonder what it is like. A famous answer from Zen Buddhism is "Nothing special." Because, in satori, void consciousness is thought to replace ego consciousness, this statement is at least ironical.

However, if putting aside the idea of extinguishing the ego, heightened consciousness may be more common than is usually thought. If one of the major indicators of being in this state is inner silence - the loss of the critically selfabsorbed, interior monologue and loss of attention to oneself - along with intensely awakening to the moment at hand, then there may be occasions when individuals experience moments of heightened awareness.

Users of psychedelics or entheogenic (spirit-awakening) substances, such as ayahausca, mescaline, or LSD, claim to have attained breakthroughs in consciousness, but many natural experiences may also lead to momentary forms of breakthrough. For example, athletes "in the zone" become self-forgetful for the moment, and, as they have often expressed, it is as if they performed unconsciously, perhaps caught in Csikszentmihalyi's flow.

Those lucky enough to be caught up in a moment of aesthetic arrest while viewing or hearing or participating in an artwork seem also to have united self and world. In the same way, the creator of art may be caught up in the fervor of inspiration in which all else melts away while he or she attempts to give form to this fleeting vision. In a sudden a crisis, many have spontaneously acted and done just the right thing, without taking time to plan their actions. These examples show that one need not be deep in prayer, suffering years of self-denial, ingesting chemicals, or chanting a mantra while in meditation in order to experience transformed consciousness.

Heightened consciousness used as a term for a permanent state of exalted spiritual awareness with a largely extinguished ego is something else again. But if there is no ego-self, there is no observer and no memory, so there is little one can say about such a state.

Gregory Michael Nixon, UNBC

\section{Suggested Further Readings}

Bentov, I. (2000). A brief tour of higher consciousness: A cosmic book on the mechanics of creation. Rochester, VT: Inner Traditions/Bear.

Csikszentmihalyi, M. (1990). Flow: The psychology of optimal experience. New York, NY: Harper and Row. 
Maslow, A. (1993). The farther reaches of human nature (2 $2^{\text {nd }}$ ed). New York, NY: Penguin. 1st edition 1971.

Suzuki, D. T. (1964). The awakening of a new consciousness in Zen. In J. Campbell (Ed.). Man and transformation: Papers from the Eranos yearbooks. Bollingen Series XXX - 5. Princeton, NJ: Princeton University Press. First published in Eranos-Jahrbücher XXIII, 1954

Warren, J. (2007). The head trip: Adventures on the wheel of consciousness. New York, NY: Random House.

Wilson, C. (2009). Super consciousness: The quest for the peak experience. London, UK: Watkins Publishing. 